\title{
Learning Through Service: Student Motivations
}

Authors: Kristine Guzak, Ph.D. Student; Kurt Paterson, Ph.D., P.E.

\section{Background}

Over the last few years, concerns have escalated among many national organizations that technical expertise is no longer solely sufficient for the development of future engineers. ${ }^{1-5}$ Additionally, in the United States engineering programs continue to struggle to attract students, especially women and minorities, despite decades of strategies to change these patterns ${ }^{6-9}$ Independent of these challenges, students have rapidly created extracurricular service efforts, of considerable note is the quick emergence of Engineers Without Borders chapters at more than 200 universities within eight years. ${ }^{10}$ In some institutions, this service involvement has fueled the creation of courses and programs that offer Learning Through Service (LTS) which seems to attract a wider range of students to engineering. A growing body of evidence advocates that LTS may provide significant advantages to engineering students, but studies to date are quite limited. ${ }^{11-15}$ As universities play catch-up to these trends, a fundamental question remains unexplored: What motivates engineering students to be engaged in service?

\section{Objectives}

This paper presents findings to the above question of student motivation from two LTS programs at Michigan Technological University: (1) iDesign, an international seniorlevel capstone design program, and (2) Peace Corp Master's International (PCMI), an international graduate-level research program. Until recently, little formal assessment data exists for either program at Michigan Tech. While anecdotal evidence regarding participant and program outcomes is compelling, questions have surfaced on specific gains (and costs) to participants as a result of choosing these international sustainable development program options instead of other possibilities. In order to promote overall sustainability of these programs, the readiness of, and potential challenges for, participants are crucial components to understand. The data analysis can provide invaluable information that could shape these programs and help lead to better comprehension of how to promote these programs to others, scale them effectively, or enhance their contributions for all stakeholders. In an effort to respond to these questions, a formal assessment program was designed and initial data acquired in the 2010-2011 academic year; this paper examines findings from this dataset.

\section{Study Participants}

Both international programs at Michigan Tech partner with rural economicallydeveloping communities in other countries, and both position the students as technical experts within a multi-stakeholder partnership for engineering infrastructure design, construction, or enhancement. Additionally, each of the programs has on-campus preparation prior to international fieldwork, and end with engineering analysis and communication. The programs are further described below. 


\section{1 iDesign: Undergraduate Program}

The undergraduate program cohort for the purposes of this study consists of 26 multidisciplinary students with a wide range in backgrounds (e.g. work experiences, travel experiences, language proficiency, etc.). As part of the program, students participate in one semester of prep work (Spring), two weeks of fieldwork in the host community (Summer), and one semester of analysis and communication (Fall). As a complementary component to the preparatory work, students underwent a mixed methods assessment before international travel (March-April, 2011) and will complete it again after the fieldwork (November, 2011). Within the scope of this assessment the students are in the process of completing the fieldwork, thus limiting the data to information prior to their departure.

\subsection{PCMI: Graduate Program}

The graduate cohort consists of 14 masters students in civil or environmental engineering students from various backgrounds (e.g. undergraduate disciplines, travel experience, volunteer experience, etc.), although four students failed to complete the assessment beyond demographic information. As part of the program students participate in two semesters of preparatory work (coursework and informally through their learning community), twenty-seven months of fieldwork (including 3 months of training), and one semester of communication (thesis defense) upon returning from fieldwork. Similar to the undergraduate students, the graduate students underwent a mixed methods assessment at the start of the program (August, 2010), but also at the conclusion of their on-campus preparation (April, 2011) before the fieldwork; they will undergo the same assessment upon returning (various points in Fall, 2013). Our assessment protocol is a longitudinal one, following students from start to finish within their program, however, this paper focuses on the assessment program design and pre-fieldwork evaluation to date.

\section{Assessment}

The assessment program consists of five mixed methods: A.) motivations, B.) intercultural awareness, C.) sustainable engineering, D.) skills and attitudes, and E.) readiness,. As part of the overall study the following instruments were used in an effort to qualitatively and quantitatively assess a better understanding of knowledge, skills, attitudes, and identity of participants. Instruments B-E could have an impact on the narrative responses to instrument A (Motivations), so that instrument is completed first by each student cohort as early as administratively possible during the on-campus preparation phase of each program. The assessment program has been reviewed and approved for use by Michigan Tech's Institutional Review Board.

\section{A. Motivations}

Comparable to many international service programs, both programs within this study are options, and demanding ones at that, hence the stated question above 
becomes especially relevant to the student, their team, and their host community. This paper focuses primarily on the motivations component of the mixed methods protocol, but connections to the other four instruments are presented where relevant. Student motivations are captured through an essay describing interest in participation, and indirectly through parts of the other four tools. The essay is motivated by a handout at a cohort meeting early in the program (for preassessment) and near the end of participation (post); task directions are general to give students a completely blank canvas for response:

Task: write a narrative, no more than one page at 12 point font, describing your motivations for wanting to participate in this program. Print out, staple to this cover sheet, and drop off.

As standard protocol, no names are allowed on returned responses, rather student's use a six-digit codename (first 2 letters of first name + first 2 letters of last name +2 numbers from birthday) across all five instruments. ${ }^{16}$

Each motivations narrative essay was transcribed, then coded using qualitative data analysis software (HyperRESEARCH 3.0) bearing in mind the question: Why are students interested in participating in these programs? ${ }^{17}$ Appendix A includes the list of codes created, including further explanations of each. Once the essays were coded they were then analyzed using a frequency reporting tool built into HyperRESEARCH. This dataset was examined using several filter options (all responses, by gender, class level, and intercultural experience). The findings of these analyses are discussed in the Results section below.

\section{B. Intercultural Development Inventory (IDI)}

Developed by the Intercultural Communication Institute, the IDI assesses intercultural competency and awareness. ${ }^{18-19}$ The IDI is an online, 50-question instrument, which creates quantitative "scores" (perceived and actual intercultural development, among other information) based on participant responses to these Likert-scale questions. This information provides insight where the individual may lie on a development scale from ethnocentrism to ethnorelativism (stages: denial, defense, reversal, minimization, acceptance, and adaptation). The IDI suggests how well the participant might work with someone who has a different worldview, culture, and life experiences; while this is important for forecasting possible project partnership successes and challenges (and can inform preparation), it is also suggestive of the framework supporting a student's motivations for participation.

\section{Sustainable Engineering Assessment}

This assessment addresses how well prepared students are to work with global engineering problems. It is comprised of two components: (1) an open-ended case study based question to measure the understanding of sustainable engineering, 
and (2) an online survey in which the motivations, self-efficacy, and mastery of sustainable engineering are addressed. ${ }^{20-21}$ The case study reflection essay is administered with the whole cohort in a room, and handwritten over a period of 30-45 minutes. The online survey is comprised of 25 Likert-scale questions that are based in sub-groups examining self-efficacy, beliefs, and knowledge of sustainable engineering. This survey typically takes students approximately 10 minutes to complete. From this assessment a better understanding of the students, possible explanations of their sustainable engineering mindset in relation to international service, as well as the effectiveness of the programs in which they were involved can be examined.

\section{Skills and Attitude Survey}

An additional, internally created (but not validated) survey, the Skills and Attitude Survey, is a student self-assessment on knowledge and skills on international engineering work. This survey is comprised of 17 Likert-scale questions and elicits responses on program involvement, reasons for involvement, skills and knowledge gained, skills and knowledge to be improved, professional and personal outcomes influenced by participation, and forecasted next steps.

\section{E. Readiness}

The Readiness Indicator is a shortened version of the 45-item instrument used to promote global competency, the Miville-Guzman University-Diversity Scale (MGUDS). ${ }^{22}$ The readiness assessment, developed for international programs at Purdue University, is comprised of 20 questions utilizing a six-point Likert scale ranging from strongly agree to strongly disagree and has been used to examine the awareness and potential acceptance of cultural similarities and differences among engineering students. ${ }^{15}$ This instrument was utilized as additional perspective on the motivations of students participating in the international programs being assessed, as well as to understand preparation effectiveness, and potential team and project partnership issues. The resulting information provides essential background information and further perspective to analyze the students' motivations.

\section{Results}

\section{A. Motivations: General Findings}

An overall frequency report of motivational codes was generated using HyperRESEARCH to better understand the male and female groupings, graduate and undergraduate programs, and three levels of international experience. In general, motivations for participation seem independent of class level, while gender or international experience have greater influence. The figures and tables below show the results of the code analyses of student motivation essays by experimental variable (gender, class, experience). Figure 1 shows the descriptive breakdown of all students in 
both programs $(n=36)$ for this investigation. The motivation analysis for all students, in the form of the eight most frequent codes (motivations for participation), is presented in Figure 1. See Appendix A for the list of all codes (motivations). While the top reason is outward-focused ("helping others"), the rest are self-focused professional and personal drivers.

Grouped differently, student motivations fall into two broad categories, idealistic and pragmatic. The top reasons presented by the first group include: wanting to make a difference, fulfilling engineering obligations to all of humanity, and understanding cultural diversity and how it influences the need for engineers. The second group typically state being motivated to: gain project management experience, leadership experience, or construction experience. A common statement was the desire to do engineering that matters to their community partners, but also to them as students. There was also a special pride in belonging to a tribe of fellow students similarly motivated to go above and beyond the required expectations for graduation. While these generalities provide an interesting first look, the remainder of the paper and presentation will provide more nuanced discoveries by gender, cultural experience, and academic level.

Additionally, a glance at the overall breakdown of the motivations of everyone involved in this study shows that there are three main motivations: helping others, personal goal, and desire to work abroad (see Appendix A for further code descriptions). A further examination of the entire group suggests that career goals, solving problems, new opportunities, hands on experience, and community need are also high motivators for students to become involved with international programs (Table 1). A further breakdown of the results can be found in a pie chart in Appendix B. As discussed within the remainder of this paper, this information can be used to encourage individual groups of students to increase the interest in these programs and continue to meet the needs of students.

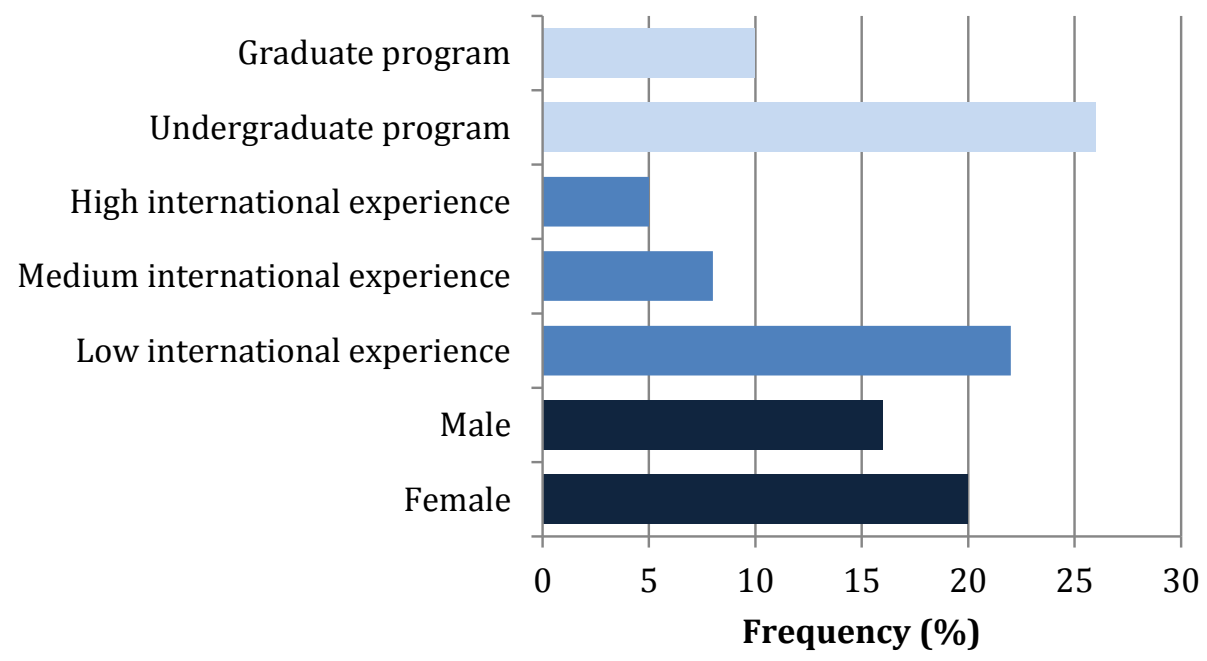

Figure 1. Student participant demographics in three categories: gender, prior international experience, and class level $(n=36)$ 
Table 1. Top motivation essay codes as response to reasons for participation in an international service program ( $n=234$ code tags for 36 student essays)

\begin{tabular}{|l|c|} 
Motivation (code) & Frequency \\
\hline Helping others & $15 \%$ \\
\hline Personal goals & $12 \%$ \\
\hline Desire to work abroad & $12 \%$ \\
\hline Career goals & $8 \%$ \\
\hline Solving problems & $6 \%$ \\
\hline New opportunities & $6 \%$ \\
\hline Hands on experience & $6 \%$ \\
\hline Community need & $6 \%$ \\
\hline
\end{tabular}

\section{B. Motivations: Gender Influences}

Despite decades of effort, the engineering field is still dominated by white men. ${ }^{6,23-24}$ Intriguingly, LTS programs, especially international ones, are disproportionately comprised of women, typically $50 \%{ }^{12-14,25}$ A better understanding of what is attracting (and retaining) females to these programs could create a pathway enabling universities to effectively create student bodies more representative of society. The evaluation of the gender-filtered code frequency reports effectively illuminate what attracts males and females to the two programs at Michigan Tech University; these are likely a representation of what could be seen at other universities in other programs similar to these, but a greater study pool will elevate the confidence of generalized findings. Figures 2 and 3 reveal demographic patterns by gender: a key finding is the female participation rate in both the undergraduate and graduate programs (54\% and $71 \%$, respectively); there is a strong interest in international programs from women, even though they tend to have less international experience than men in these programs (Figure 3). Further analysis of the motivations suggest that the top three reasons are exactly the same (but in slightly different order), although the break down for fourth and fifth reasons are different. Males and females alike agree that helping others, their desire to work abroad, and their own personal goal are the main three reasons that motivate them to participate in these programs. These top three reasons account for $40 \%$ of the motivation reasons mentioned by males and about $38 \%$ of those from females.

Due to the similarity of the responses for the top three reasons, the fourth and fifth ranked reasons (many reasons have tied for each place) were further examined. For the males these include alignment with career goals, the desire for a new opportunity, getting hands on experience and a desire for an unconventional job after graduation. For the females this includes the desire to help a community with their needs, career goal, the influence from a class they had taken (university or high school), and hands-on experience. Some similarities between males and females are evident in this second tier of reasons, but the few differences are noteworthy. Classes have an impact on females in a way that they do not for males, universities should work to attract women to these kinds of programs through positive classroom experiences (e.g. relating engineering practice to helping 
communities). In general many men might be receptive to messaging about the professional value to be gained from these new and challenging experiences.
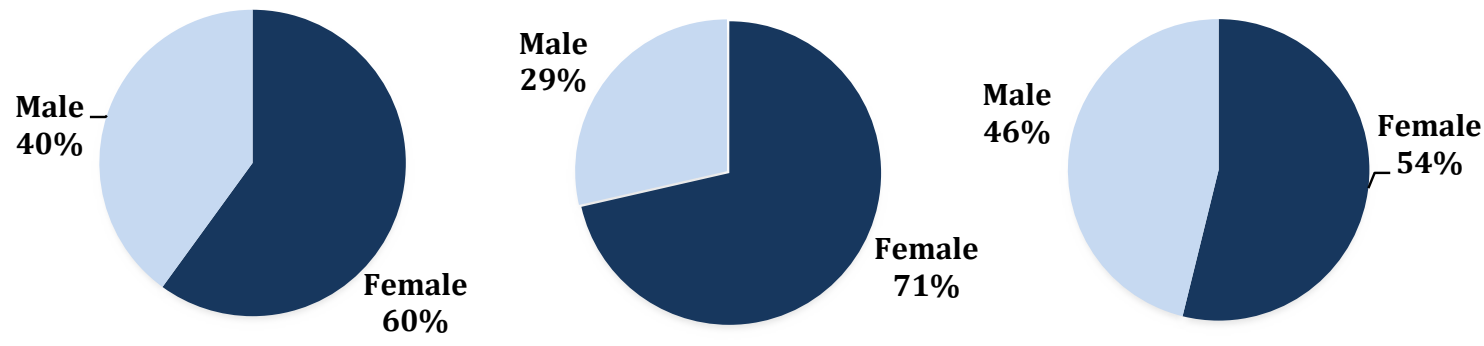

Figure 2. Gender breakdown for (left to right): all participants $(n=40)$, graduate program $(\mathrm{n}=14$; four women did not complete all aspects of assessment but are included here), and undergraduate program $(n=26)$
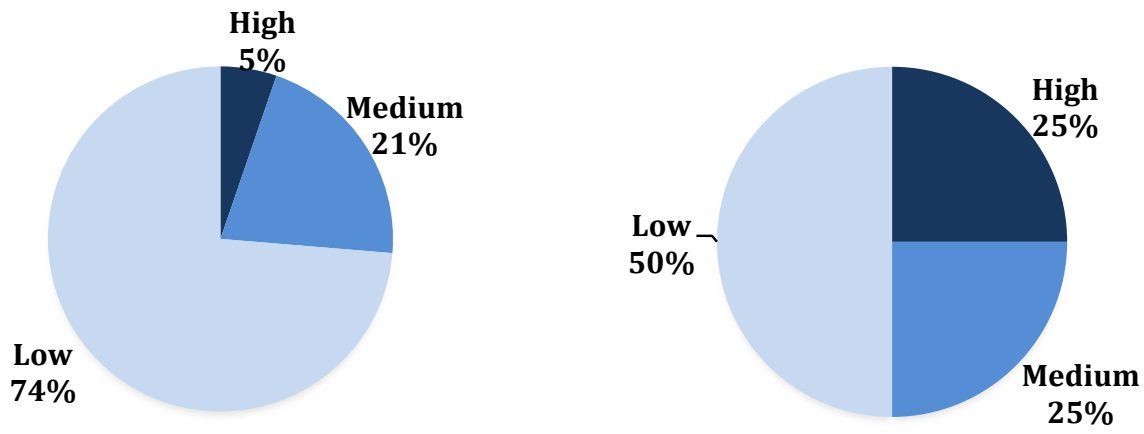

Figure 2. International experience for (left to right): all women $(n=23)$ and all men $(n=16)$. Low is 0 to 10 weeks, medium is 10 to 30 weeks, and high is greater than 30 weeks of living and traveling internationally.

Table 2. Top five motivations expressed by men and women; rank (frequency), $n=234$ code tags within 36 student essays

\begin{tabular}{|l|c|c|}
\multicolumn{1}{|c|}{ Motivation } & $\begin{array}{c}\text { Male Rank } \\
\text { (frequency) }\end{array}$ & $\begin{array}{c}\text { Female Rank } \\
\text { (frequency) }\end{array}$ \\
\hline Helping others & $1(16 \%)$ & $1(15 \%)$ \\
\hline Personal goals & $3(10 \%)$ & $2(13 \%)$ \\
\hline Desire to work abroad & $2(14 \%)$ & $3(10 \%)$ \\
\hline Career goals & $4(8 \%)$ & $4(8 \%)$ \\
\hline New opportunities & $4(8 \%)$ & \\
\hline Desires unconventional job & $5(7 \%)$ & \\
\hline Hands on experience & $5(7 \%)$ & $5(6 \%)$ \\
\hline Community need & & $4(8 \%)$ \\
\hline Class influence & & $5(6 \%)$ \\
\hline Solving problems & & $5(6 \%)$ \\
\hline
\end{tabular}




\section{Motivations: Academic Level Influences}

Statistics also reveal that fewer students are pursuing higher level degrees and that the majority finish their undergraduate program and go directly into the work force. ${ }^{26-27} \mathrm{As}$ part of the graduate program within this study, students have the option to pursue a higher level degree while gaining international experience. Understanding what the motivations are of the two levels of students might help encourage students to explore these experiences and continue their education at the graduate level. The motivations of each level of student were analyzed within this study and found that although the graduate program has lower numbers, it attracts a individuals with higher international experience (even normalized for age; data not shown). The same top three reasons as with males and females were found to be the case for undergraduates and graduates; they are motivated by helping others, their desire to work abroad, and their own personal goals.

Since the top reasons were insensitive to class level, the second tier reasons were further examined. Undergraduates were found to be motivated by their career aspirations whereas graduates were motivated by more intrinsic factors (the influence of a class, desire to solve pressing problems, interest in overcoming difficult struggles, the satisfaction associated with being part of a well-regarded program, and the interest in having an unconventional career). It is clear that the reasoning between these two levels require a very different approach in attracting more individuals to these programs. Graduate level students require evidence (based on their philosophical, moral, ethical views) that the program offers an opportunity to engineer a difference, whereas many undergraduates want to see the professional development advantages of participation. Graduate students need more complex incentives to continue their education than undergraduates do since their objectives are less career and more personal. Targeting graduate students in the classroom and appealing to their interests to show them that there are other options than simply getting a degree and joining the traditional work force is essential for expanding programs like these.
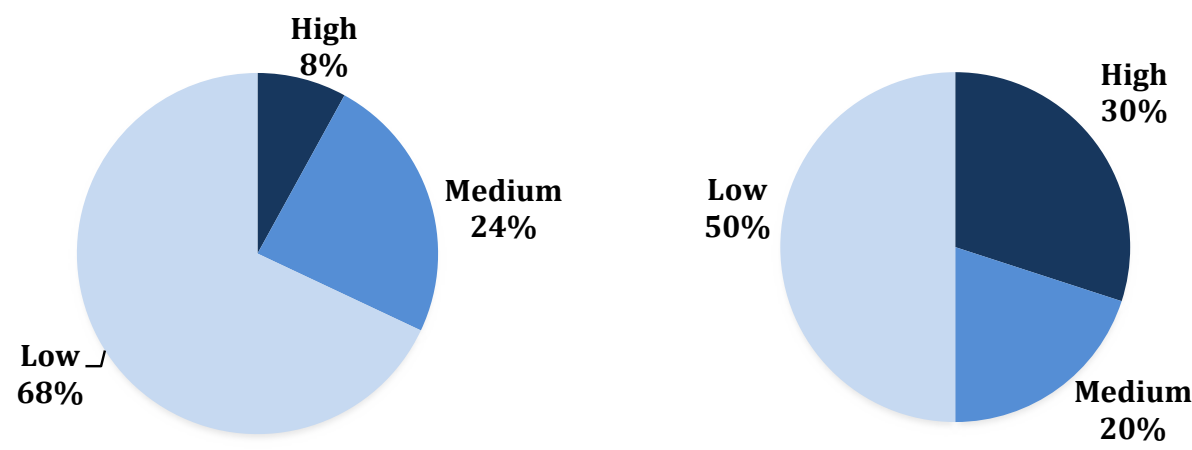

Figure 4. International experience for (left to right): all undergraduates $(\mathrm{n}=25)$ and all graduate students $(\mathrm{n}=10)$. Low is 0 to 10 weeks, medium is 10 to 30 weeks, and high is greater than 30 weeks of living and traveling internationally. 
Table 4. Top four motivations expressed by undergraduate and graduate students; rank (frequency), $n=234$ code tags within 36 student essays

\begin{tabular}{|l|c|c|} 
Motivation & $\begin{array}{c}\text { Undergraduate } \\
\text { rank (frequency) }\end{array}$ & $\begin{array}{c}\text { Graduate } \\
\text { rank (frequency) }\end{array}$ \\
\hline Helping others & $1(17 \%)$ & $2(12 \%)$ \\
\hline Personal goals & $3(10 \%)$ & $1(15 \%)$ \\
\hline Desire to work abroad & $2(12 \%)$ & $2(12 \%)$ \\
\hline Career goals & $4(9 \%)$ & \\
\hline Desires unconventional job & & $4(6 \%)$ \\
\hline Class influence & & $3(8 \%)$ \\
\hline Solving problems & & $3(8 \%)$ \\
\hline Program reputation & & $4(6 \%)$ \\
\hline Personal struggle & & $4(6 \%)$ \\
\hline
\end{tabular}

\section{Motivations: Intercultural Experience Influences}

Once students become involved with international programs it is often difficult to go back to their daily lives without craving more. Students who have previously had international opportunities were also analyzed to determine what their motivations were for becoming involved with each of these two programs. The hope was that gathering information about whether an additional international experience was enough to attract the student or if they had alternative motivations. Students were broken up into three categories for this category of analysis: low (0 to 10 weeks), medium (10 to 30 weeks) and high (above 30 weeks) international experience. The frequency results show these programs attract a fair amount from each level with the graduate program attracting more experienced students (see Figure 4 above; note that one undergraduate female did not answer this question). In fact the undergraduate program is the first international experience for $20 \%$ of the cohort (all graduate program students had at least two weeks of travel abroad prior to start). Some students are interested in sampling such experiences for the first time, many others are returning for more. If the experiences are positive (and challenging based on motivations listed by graduate students in Table 4, for example), the biggest hurdle is crafting first experiences, then a virtuous cycle of involvement can be catalyzed.

Similarly to previous sections, top reasons for all international experience levels are helping others, desire to work abroad, and personal goal. Yet further examination reveals a few interesting differences. Desire to help others decreases with experience, this may be rooted in an appreciation of the realities of development work (partnership oriented vs. "helping"). The most experienced students ranked a desire to work abroad most highly. From these preliminary observations it seems that new (less experienced) students may connect more with an "engineering philanthropy" goal, whereas experienced students are looking for "engineering development." Regardless of their mindset, encouraging students to become involved with these programs because of the opportunity to gain valuable experience should be attractive. 
Table 5. Top three motivations expressed by students with low, medium, and high international experience; rank (frequency), $n=234$ code tags within 36 student essays

\begin{tabular}{|l|c|c|c|}
\multicolumn{1}{|c|}{ Motivation } & $\begin{array}{c}\text { Low rank } \\
\text { (frequency) }\end{array}$ & $\begin{array}{c}\text { Medium rank } \\
\text { (frequency) }\end{array}$ & $\begin{array}{c}\text { High rank } \\
\text { (frequency) }\end{array}$ \\
\hline Helping others & $1(17 \%)$ & $1(14 \%)$ & $2(13 \%)$ \\
\hline Personal goals & $2(13 \%)$ & $2(10 \%)$ & $3(10 \%)$ \\
\hline Desire to work abroad & $3(12 \%)$ & $2(10 \%)$ & $1(16 \%)$ \\
\hline Career goals & & $1(14 \%)$ & $3(10 \%)$ \\
\hline Class influence & & $3(8 \%)$ & \\
\hline Hands-on experience & & & $3(10 \%)$ \\
\hline Program reputation & & $3(8 \%)$ & \\
\hline
\end{tabular}

\section{Conclusions}

The assessment strategy and its five instruments used to assess students within the undergraduate and graduate programs help to begin gathering information about what motivates students to participate in international programs like these. It is easy to overgeneralize, exceptions always exist, but in general students are attracted for altruistic (helping) or pragmatic (experience) reasons; in general women and students with less experience are motivated by the former, men and students with more international experience the latter. In addition to determining what motivates students to participate in these programs the sustainability of these programs relies on consistent (or growing) student demand, the readiness of the participants, and the preparation resources needed. The motivations analyzed within this study can indicate where efforts should be focused to meet the needs of students to encourage their participation; a mixed message campaign would work best, targeting practical and idealistic outcomes. This preliminary assessment completed at Michigan Tech University will be continued to assess post-program attitudes, expanded to other similar international programs within the university, and offered to other universities, all with a desire to best practices in international programs and enhance the sustainability such programs. ${ }^{28}$ The essential component to take away from this study is what gets measured is what gets improved: understanding student motivations benefits all involved.

\section{References}

1. Boyer, E. L. (1996). The Scholarship of Engagement. Bulletin of the American Academy of Arts and Sciences, 49(7):18-33.

2. Grandin, J. M., and E.D. Hirleman. (2009). Educating Engineers as Global Citizens: A Call for Action / A Report of the National Summit Meeting on the Globalization of Engineering Education. Online Journal of Global Engineering Education. 4(1): 10-25. Available at http://digitalcommons.uri.edu/ojgee/vol4/iss1/1/ (Accessed August 9, 2011)

3. Katehi, L. The Global Engineer (2005). In Educating the Engineer of 2020: Adapting Engineering Education to the New Century (151-155). The National Academies Press, Washington, DC.

4. Sigma Xi. Embracing Globalization: Assuring a Globally Engaged Science and Engineering Workforce 
(Workshop Report). Sigma Xi, Washington, DC. 2007.

5. Vest, C.M. (2006). Educating Engineers for 2020 and Beyond. The Bridge: Linking Engineering and Society. National Academy of Engineering. 36(2):38-44

6. Jordan, K.L., Amato-Henderson, S., Sorby, S.A. and T.L. Haut Donahue (2011). Are there differences in self-efficacy between minority and majority students across academic levels? Proceedings of the American Society for Engineering Education Annual Conference. Vancouver, BC. AC2011-659. 13 pp.

7. National Science Foundation (2011). Women, Minorities, and Persons with Disabilities in Science and Engineering: 2011, National Science Foundation, Arlington, VA. 16 pp.

8. Seymour, E. and N. Hewitt (2000). Talking About Leaving: Why Undergraduates leave the Sciences, Westview Press, Boulder, Colorado. 444 pp.

9. Tinto, V. (1994). Leaving College: Rethinking the causes and cures of student attrition. University of Chicago Press. 312 pp.

10. Paterson, K., C. O’Holleran, and C. Leslie (2010). Faculty Impressions of Service Learning in Engineering Education. Proceedings of the American Society for Engineering Education Annual Conference. Louisville, KY. AC2010-2033, 8 pp.

11. Silliman, S., R.Mohtar, K.G. Paterson, and W. Ball (2010). Engineering Academic Programs for Hydrophilanthropy: Commonalities and Challenges. Journal of Contemporary Water Research and Education. 145:5-29. (I)

12. Bielefeldt, A.R., K.G. Paterson, and C.W. Swan (2010). Measuring the Value Added from Service Learning in Project-Based Engineering Education. International Journal of Engineering Education. In Special Issue on Problem-Based Learning, 26(3):1-12. (I)

13. Paterson, K.G. and V.J. Fuchs (2008). Development for the Other 80\%: Engineering Hope, Australasian Journal of Engineering Education. 14(1):1-12.

14. Parkinson, A. Engineering Study Abroad Programs: Formats, Challenges, Best Practices. Global Journal of Engineering Education, 2(2): 1-15.

15. Jesiek, B.K., Chang, Y., Shen, Y., Lin, J.J.J., Hirlemann, E.D., and E.A. Groll (2011). International Research and Education in Engineering (IREE) 2010 China: Developing Globally Competent Engineering Researchers. Proceedings of the American Society for Engineering Education Annual Conference. Vancouver, BC. AC2011-1975. 14 pp.

16. Paterson, K. and C. Swan (2011). ISES-A Longitudinal Study to Measure the Impacts of Service on Engineering Students. Proceedings of the American Society for Engineering Education Annual Conference. Vancouver, BC. AC2011-1328.

17. ResearchWare, Inc. (2010). HyperRESEARCH User Guide, ver.3. Randolph, MA. 171 pp.

18. Bennett, M. J. (1993). Towards ethnorelativism: A developmental model of intercultural sensitivity, in R. M. Paige (Ed.), Education for the intercultural experience, Intercultural Press, Yarmouth, ME, pp. 21-71.

19. Hammer, M.R., M.J. Bennett and R. Wiseman (2003). Measuring intercultural sensitivity: The intercultural development inventory. International Journal of Intercultural Relations. 27(4): 421-443.

20. McCormick, M., C. Swan, A. Bielefeldt, K. Lawyer, K. Paterson (2011). Service Learning: Motivating students to engineer sustainably. Proceedings of the American Society for Engineering Education Annual Conference. Vancouver, BC. AC2011-1335.

21. McCormick, M., K. Lawyer, M. Berlin, C. Swan, K. Paterson, A. Bielefeldt, and J. Wiggins (2010). Evaluation of Sustainable Engineering Education via Service Learning and Community Service Efforts. Proceedings of the American Society for Engineering Education Annual Conference. Louisville, KY. AC2010-1102, 10 pp.

22. Miville, M. L., Gelso, C. J., Pannu, R., Liu, W., Touradji, P., Holloway, P., et al. (1999). Appreciating similarities and valuing differences: The Miville-Guzman Universality-diversity Scale. Journal of Counseling Psychology, 46 (3), 291-307.

23. National Academy of Engineering (2008). Changing the Conversation: Messages for Improving Public Understanding of Engineering, Committee on the Public Understanding of Engineering Messages. National Academies Press, Washington, DC. 149 pp.

24. Besterfield-Scare, M., Moreno, M., Shuman, L., and C. Atman (2001). Gender and ethnicity differences in freshmen engineering student attitudes: a cross-institutional study. Journal of Engineering Education. 90(4):477-489.

25. Busch-Vishniac, I. J. and J. P. Jarosz (2004). Can Diversity in the Undergraduate Engineering Population Be Enhanced Through Curricular Change? Journal of Women and Minorities in Science and 
Engineering, 10(3):50-77.

26. National Science Board (2008). Science and Engineering Indicators 2008. Volumes 1 and 2. National Science Foundation, Arlington, VA. 1164 pp.

27. National Science Foundation (2011). Women, Minorities, and Persons with Disabilities in Science and Engineering: 2011, National Science Foundation, Arlington, VA. 16 pp.

28. National Academy of Engineering (2009). Developing Metrics for Assessing Engineering Instruction: What gets measured is what gets improved. National Academy Press, Washington, DC. 52 pp.

\section{Biographic Information}

KURT PATERSON, Associate Professor of Civil and Environmental Engineering, is also a director of several international programs at the undergraduate and graduate levels. He strives to be an educational innovator, adding intriguing courses to the curriculum. He is PI/co-PI, on several large projects assessing the impacts of learning through service on students, faculty, and communities around the world.

KRISTINE GUZAK is a Ph.D. student of Environmental Engineering at Michigan Technological University. She is the lead graduate student on a larger project assessing the impacts of learning through service on undergraduate students. Her research interests include Engineering Education with some focuses on international programs. 


Appendix A: Code Descriptions
\begin{tabular}{|l|l|}
\hline Career goal & Personal ambition, international experience will help with resume or other forms of career aspirations \\
\hline Class influence & Within a class it was suggested that international experiences are beneficial \\
\hline Community need & A desire to work with people to get them what they need as opposed to giving them what is thought they need \\
\hline Desire to work abroad & Personal ambition to work outside of the United States \\
\hline Desires unconventional job & Personal ambition to work in a setting that is atypical of the engineering 9 to 5 job \\
\hline Efficient aid & A desire to work with the people to get them what they need even if this means not personally traveling \\
\hline Family influence & Family members suggest the importance of international experiences \\
\hline Hands on experience & A desire to use the material learned in class out in the field to solve real problems \\
\hline Helping others & A desire to assist people other than oneself \\
\hline Mentor & An outside source like a professor or advisor suggests that international experiences are useful \\
\hline New opportunity & The prospect of experiencing something outside the ordinary \\
\hline Personal goal & Individual ambition to do something internationally \\
\hline Personal struggle & Individual problems one must overcome while working internationally \\
\hline Religion & A religious belief impacts the desire to work abroad through the desire to help, teach, learn, etc. \\
\hline Solving problems & A desire to work with circumstances to overcome obstacles others face \\
\hline Successful reputation & The reputation of the international program precedes itself, encouraging students to participate \\
\hline Volunteering & The desire to give one's time \\
\hline Working with people & The desire to work with others to reach a common goal and learn from each other \\
\hline
\end{tabular}



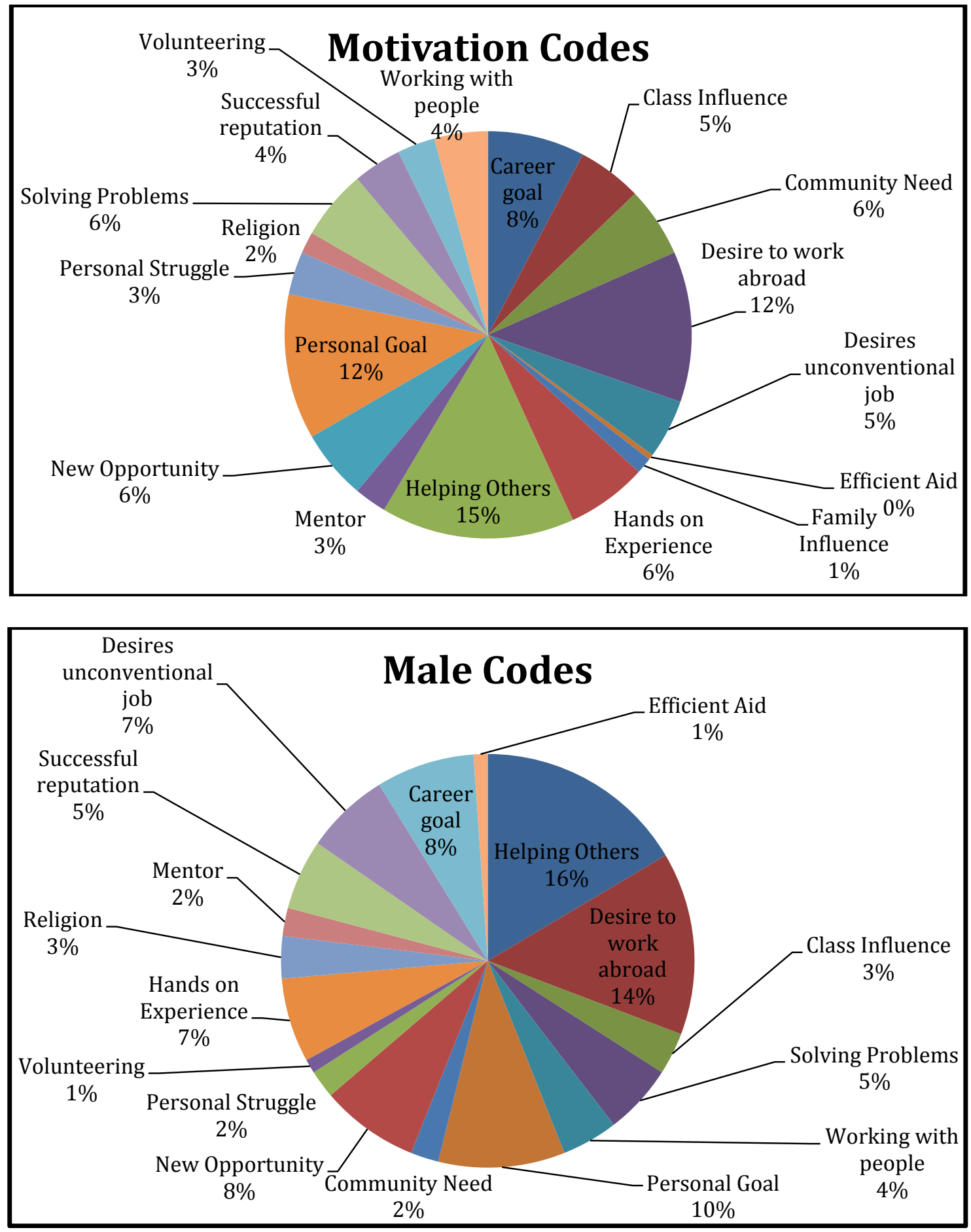


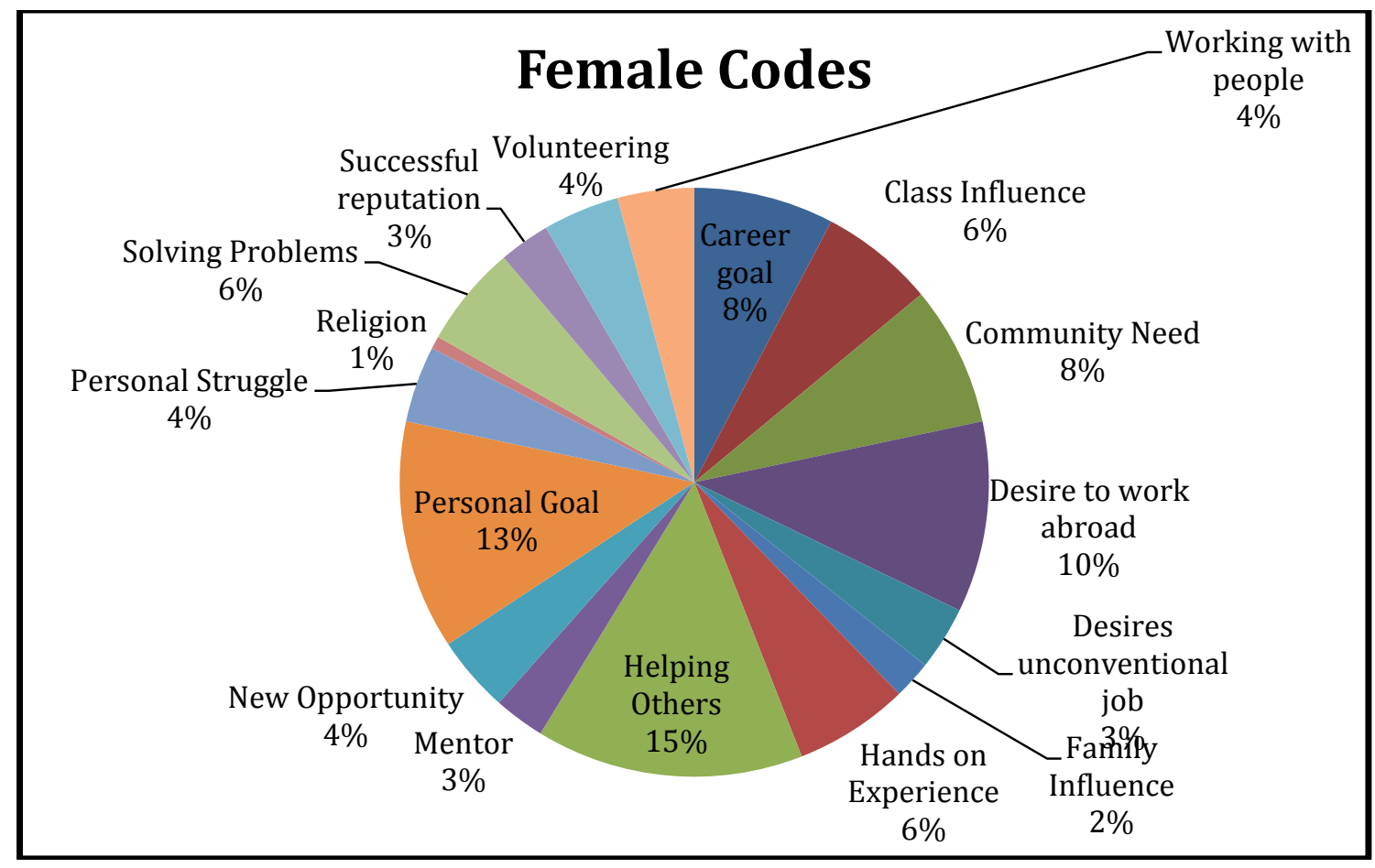

